\title{
Evaluation of cotton cultivars based on the compensatory increase of cotton squares after simulating damage by the cotton boll weevil
}

\author{
Bruna Laís Nascimento Alves ${ }^{1}$ (D), Carlos Alberto Domingues da Silva ${ }^{1,2, *}$ (D), José Eduardo Serrão ${ }^{3}$ (D), \\ José Cola Zanuncio ${ }^{3}$ (D) \\ 1. Universidade Estadual da Paraíba - Programa de Pós-Graduação em Ciências Agrárias - Campina Grande (PB), Brazil. \\ 2. Embrapa Algodão - Laboratório de Entomologia - Campina Grande (PB), Brazil. \\ 3. Universidade Federal de Viçosa - Departamento de Entomologia - Viçosa (MG), Brazil. \\ Received: Feb. 4, 2021 | Accepted: Jul. 1, 2021 \\ Section Editor: Carlos Alberto Scapim \\ *Corresponding author: carlos.domingues-silva@embrapa.br \\ How to cite: Alves, B. L. N., Silva, C. A. D., Serrão, J. E. and Zanuncio, J. C. (2021) Evaluation of cotton cultivars based on the compensatory \\ increase of cotton squares after simulating damage by the cotton boll weevil. Bragantia, 80, e4621. https://doi.org/10.1590/1678-4499.20210036
}

\begin{abstract}
The objective of this study was to evaluate cotton cultivars based on the compensatory increase of cotton squares in response to the simulation of the boll weevil damage. The first experiment aimed to evaluate cotton cultivars with greater compensatory increase in squares removed artificially from the plant. The experimental design was in randomized blocks, in a $4 \times 2$ factorial scheme with $100 \%$ removal of cotton squares at 50, 70 and 90 days after the emergence of the FM975WS, TMG81WS, IMA6501B2RF and BRS432B2RF cotton cultivars and passive production (without removal) and active (with removal) of cotton squares, with four replications. In the second experiment, boll weevil damage in the TMG80WS and BRS432B2RF, with greater and lesser compensatory increase of cotton squares, after their removal at 50 days of age, was evaluated. The experimental design was in randomized blocks, in a $2 \times 2$ factorial scheme, with the former cultivars sprayed with carbamate or not (control). The compensatory increase of cotton squares, mainly after their artificial removal at 50 and 70 days of age, of the TMG81WS, was greater. The cotton square compensatory increase after being artificially removed in the cotton cultivars was higher during the period of exponential production of these reproductive structures and can be used to select cultivars tolerant to boll weevil damage.
\end{abstract}

Key words: Anthonomus grandis, Gossypium hirsutum, plant resistance to insects, tolerance.

\section{INTRODUCTION}

Insect pests of agricultural importance introduced to Brazil cause economic losses (Oliveira et al. 2013), with emphasis on the cotton boll weevil, Anthonomus grandis Boheman (Coleoptera: Curculionidae) (Salvador et al. 2014). This insect, with high reproductive capacity and three to seven generations per crop (Oliveira et al. 2013), modifies the plant vegetative development and destroys its reproductive structures, compromising the cotton fiber production and quality (Silva and Ramalho 2013; Silva and Silva 2015).

Resistant varieties stand out in the management of the cotton boll weevil. The conventional breeding program of Embrapa Algodão, since the late 1980s, aims to obtain resistant genotypes in Brazil from primitive breeds of this plant from Mexico and Central America (Carvalho et al. 1996). This program basically develops cotton cultivars with short cycle and fast maturation to reduce the exposure period and the colonization and infestation by insect pests, particularly the boll weevil (Silva et al. 2013).

Genetic engineering, with the availability of Bt cotton cultivars resistant to lepidopteran pests, reduced the conventional breeding programs of this plant (Anderson et al. 2019; Rocha-Munive et al. 2018). However, the need to spray insecticides to combat the cotton boll weevil in improved plants increases cotton production costs. 
The selection of resistant cotton plants against cotton boll weevil, via conventional genetic breeding, is important due to the technical difficulties of obtaining cultivars, genetically modified and resistant to this insect (Anderson et al. 2019). Cotton tolerates and/or compensates insect pest injuries in its reproductive structures (Knutson et al. 2013; Koch et al. 2016). This compensation depends on several factors, including the time and intensity of the injury, the physiological age of the injured structure, the cotton cultivar and the environment in which the cotton is grown (Peterson et al. 2017; Sadras 1995). However, there are few studies using this compensatory capacity to select cotton cultivars that are tolerant to damage caused by boll weevil on cotton squares.

The hypothesis of this study is that there is genetic variability between cotton cultivars to actively produce a larger number of cotton squares in response to the attack by $A$. grandis. The objective of this research was to evaluate cotton cultivars based on the compensatory increase of cotton squares at 50, 70 and 90 days after the emergence of the plants in response to the damage by cotton boll weevil.

\section{MATERIAL AND METHODS}

\section{Experiment location}

The experiments were conducted in a greenhouse $\left(7^{\circ} 13^{\prime} 35^{\prime \prime} \mathrm{S}, 35^{\circ} 54^{\prime} 21^{\prime \prime} \mathrm{W}\right)$ without access to the cotton boll weevil and in the field $\left(7^{\circ} 13^{\prime} 31^{\prime \prime} \mathrm{S}, 35^{\circ} 54^{\prime} 25^{\prime \prime} \mathrm{W}\right)$ in an experimental area at Embrapa Algodão with a history of occurrence of this insect in the municipality of Campina Grande, Paraíba, Brazil in 2019. The first experiment aimed to evaluate cotton cultivars according to the increase compensatory effect of cotton squares, artificially removed from the plant, without considering the natural abscission and the second evaluated the damage by the cotton boll weevil in cotton cultivars selected in the first.

\section{Cotton cultivars}

Seeds of the cotton cultivars FM975WS and TMG81WS, of late cycle, and the IMA6501B2RF and BRS432B2RF, of medium to late cycle, were obtained from the Active Germplasm Bank of Embrapa Algodão. The Bollgard (B2RF) and Widestrike (WS) technologies contain two Bt genes, but share only CrylAc. The other B2RF gene is Cry2Ab and the WS genes are Cry1F and Vip3A. The seeds of these cotton were sown in sachets $(9 \times 18 \mathrm{~cm})$ for seedling production, which were transplanted and cultivated in the soil in a greenhouse with an area of $65.6 \mathrm{~m}^{2}$ ( $4 \mathrm{~m}$ wide $\times 16.4 \mathrm{~m}$ long) in January 7 , 2019 in the first experiment, and in the field in an area of $200 \mathrm{~m}^{2}(10 \mathrm{~m}$ wide $\times 20 \mathrm{~m}$ long) in May 30, 2019 in the second experiment. These cultivars were chosen because their cycles are similar with average productivity above $4,500 \mathrm{~kg} \cdot \mathrm{ha}^{-1}$ of seed cotton and are planted by Brazilian producers in the Cerrado biome.

\section{Cotton selection based on compensatory increase in cotton squares}

The cotton plants were selected according to the compensatory increase of cotton squares, artificially removed from the plant grown in the soil, in a greenhouse without damage by the cotton boll weevil, lepidopteran-pest caterpillars or the cotton stainer bug.

The experimental design was in randomized blocks, in a $4 \times 2$ factorial scheme, with the four cotton cultivars mentioned, removal of $100 \%$ of cotton squares at 50, 70 and 90 days after the emergence of the plants and by the types of passive production (control, without removal) and active (removal of cotton squares) with four replications (blocks). The cotton squares were removed only once during a pre-established period.

The mean of the total number of cotton squares produced $\left(\mathrm{M}_{\text {tncsp }}\right)$ was based in the sum of the total number of cotton squares produced and removed per cultivar and predetermined period.

The mean of the total number of cotton squares actively produced $\left(\mathrm{M}_{\text {tncsap }}\right)$ per removal period was calculated with Eq. 1, adapted from Abbott (1925) and Knutson et al. (2013). 


$$
\mathrm{M}_{\text {tncsap }}=\frac{\mathrm{M}_{\text {tncsp }}-\mathrm{M}_{\text {tncspp }}}{100-\mathrm{M}_{\mathrm{tncspp}}} \times 100
$$

where $M_{\text {tncspp }}$ is the mean of the total number of cotton squares passively produced (control, without removal) in the same removal period $\mathrm{x}$.

Compensation (estimated in percentage) is the mean of the cotton squares actively produced in a given removal period divided by the total produced per cultivar in this period, multiplied by 100, being determined by Eq. 2 .

$$
\text { Comp }=\frac{M_{\text {tncsap }}}{M_{\text {tncsp }}} \times 100
$$

The parcels were composed by a row ( $4 \mathrm{~m}$ long), each with the four cotton cultivars mentioned spaced $0.90 \times 0.10 \mathrm{~m}$ $\left(110,000\right.$ plants $\left.\mathrm{ha}^{-1}\right)$. The cotton squares, produced by the cotton, per meter of row, were artificially removed from the plant in the pre-established periods using pruning shears, previously disinfected with absolute alcohol.

The cotton seeds were treated with thiamethoxan (Cruiser $700 \mathrm{WS}$ ) at a dose of $3 \mathrm{~g} \cdot \mathrm{kg}^{-1}$ of seeds, which controlled aphids, whiteflies and mites until 40 days after the emergence of the plants and, after that period, the botanical insecticide based on Nicotiana tabacum was used, when necessary. The normal cultural practices, necessary for crop cultivation (fertilization based on soil analysis, manual weeding, etc.), were carried out.

The number of cotton squares removed, produced, replaced and compensated, in an active and passive way in all cotton plants per meter of the rows in the two meters of each plot, was counted every ten days. The cotton squares were counted and marked with colored cloth ribbons to avoid recounting them.

\section{Cotton boll weevil damage evaluation per cotton cultivar}

The majority of the research on the compensatory capacity of cotton has been carried out by artificially removing cotton squares at 50 days of age. For this reason, cultivars with greater and lesser compensatory increase of cotton squares removed artificially from plants with this same age and selected in the first experiment were chosen to be used in this experiment. These cultivars were planted in the Embrapa Algodão experimental field in an area infested by the cotton boll weevil.

The experimental design was in randomized blocks with a $2 \times 2$ factorial scheme with cotton cultivars and treatments sprayed with carbamate (Metomil $216 \mathrm{SL}$ ) at 172 gram of active ingredient (g.a.i.). ha $^{-1}$ when the cotton boll weevil reached the control level or without spraying (control). The parcel was $3.90 \mathrm{~m}$ long with 32 cotton rows, half of which cultivated with cultivar of the greater and the other, with that of lower compensatory growth spaced $0.70 \times 0.10 \mathrm{~m}\left(140,000\right.$ plants.ha $\left.^{-1}\right)$ with four replications. The sucking insects and mites were controlled with sprays of thiamethoxan (Actara $250 \mathrm{WG}$ ) at 100 g.a.i.ha ${ }^{-1}$ and abamectin (Vertimec $18 \mathrm{CE}$ ) at 7.2 g.a.i. ha ${ }^{-1}$, respectively.

The population level and the spatial distribution of the cotton boll weevil adults in the experimental area were determined before the start of periodical evaluations in the cotton crop. Five eight-day old pregnant cotton boll weevil females were released per parcel, totaling 80 boll weevil females per treatment, due to the reduced number of specimens of this insect in the area.

The presence or not of the punctures by feeding and/or oviposition of the boll weevil was evaluated every five days in a medium-sized cotton square (4-6 mm in diameter), collected per plant in the upper half of the canopy in 20 plants at random, per plot in a zigzag path (Silva et al. 2013).

The spraying against the cotton boll weevil was carried out when cotton squares, with punctures of the feeding and/or oviposition, were observed in $10 \%$ of the plants and, also, after the appearance of the first cotton squares until the formation of the first boll, using a manual backpack sprayer with capacity for $20 \mathrm{~L}$ of syrup and empty cone type D2 nozzle. The spray nozzle was positioned, laterally, in relation to the cotton rows about $20 \mathrm{~cm}$ from the plants (Ramalho and Jesus 1988) with flow adjusted according to the growth stage of the plants, from 150 to $200 \mathrm{~L}$ of water solution.ha ${ }^{-1}$. The normal cultural practices, necessary for crop cultivation (fertilization based on soil analysis, manual weeding, etc.), were carried out.

The mean percentages of cotton squares damaged with punctures of feeding and/or oviposition of the cotton boll weevil, and the means of the number of medium sized bolls $(28-32 \mathrm{~mm}$ in diameter) and the cotton yield were determined. The yield was estimated by weighing the cotton plume with seed harvested manually from the bolls of all plants per plot. 


\section{Data analysis}

The means of the numbers of cotton squares removed, replaced, produced in an active and passive manner and compensated per date of removal, in the first experiment, and the means of the percentages of punctured cotton squares by the boll weevil feeding and/or oviposition, and the cotton production $\left(\mathrm{kg} \cdot \mathrm{ha}^{-1}\right)$ per plant, in the second, were subjected to analysis of variance and the means compared by the Student-Newman-Keuls test at 5\% probability. The data were analyzed with the system of statistical and genetic analysis (SAEG) (Ribeiro Junior 2001).

\section{RESULTS}

\section{Cotton selection based on compensatory increase in cotton squares}

The means of the number of cotton squares removed were similar between cotton cultivars at $50\left(\mathrm{~F}_{3,105}=0.99 ; \mathrm{p}>0.05\right)$, $70\left(\mathrm{~F}_{3,105}=1.05 ; \mathrm{p}=0.37\right)$ and $90\left(\mathrm{~F}_{3,105}=1.27 ; \mathrm{p}=0.29\right)$ days of the plant age (Fig. 1a-c).
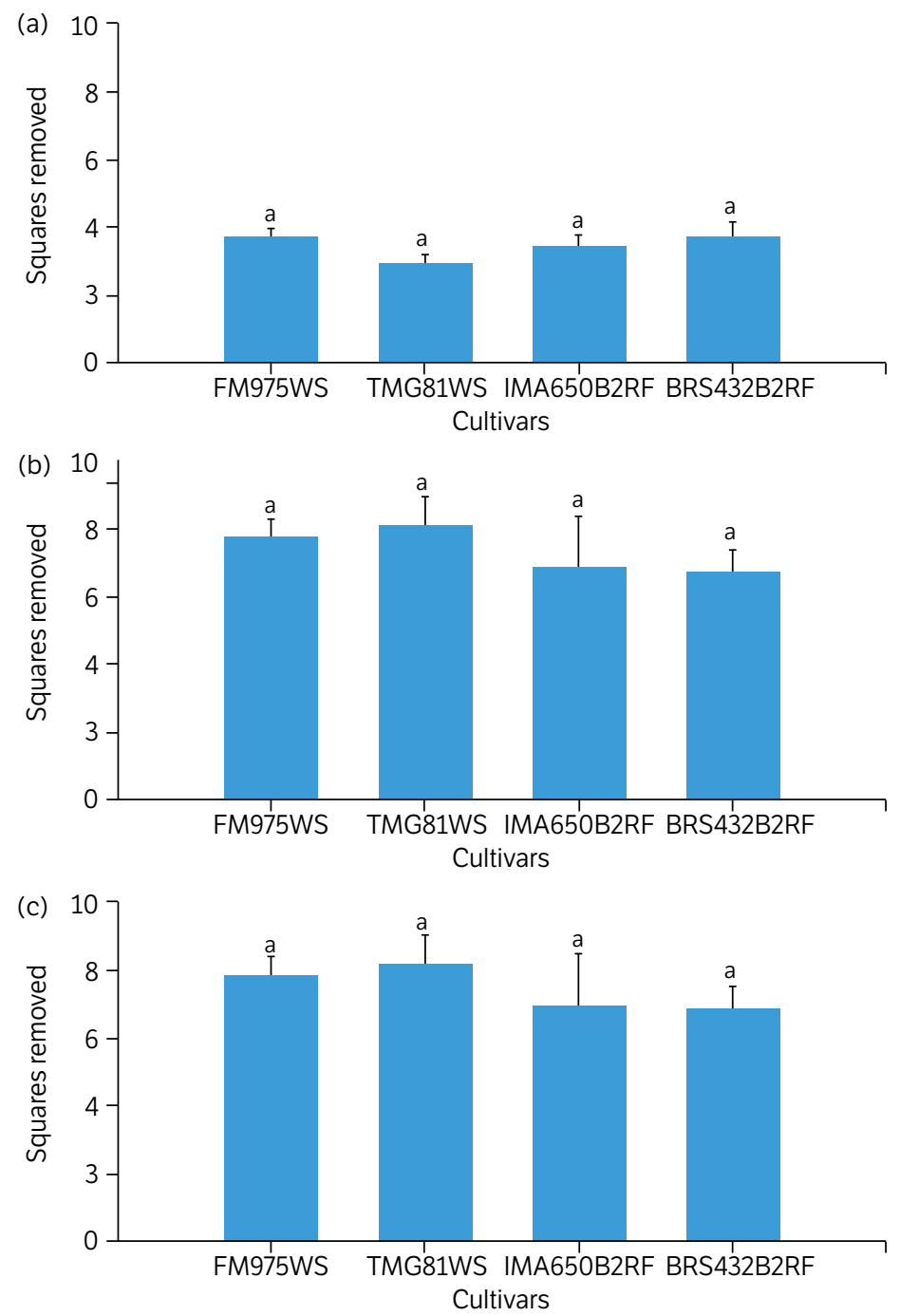

Figure 1. Number of cotton squares removed per cotton plant at 50 (a), 70 (b) and 90 (c) days of age.

Note. Means followed by the same lowercase letter, per bar and date do not differ between cotton cultivars by the Student-Newman-Keuls test at $5 \%$ probability. Means transformed into $\sqrt{ } x+0.5$ for statistical analysis. Original means are shown. 
The means of cotton squares, replaced after their removal at 50, 70 and 90 days, were higher, respectively, in the IMA6501B2RF, FM975WS and BRS432B2RF and lower in the BRS432B2RF, TMG81WS and IMA6501B2RF (Fig. 2a-c).
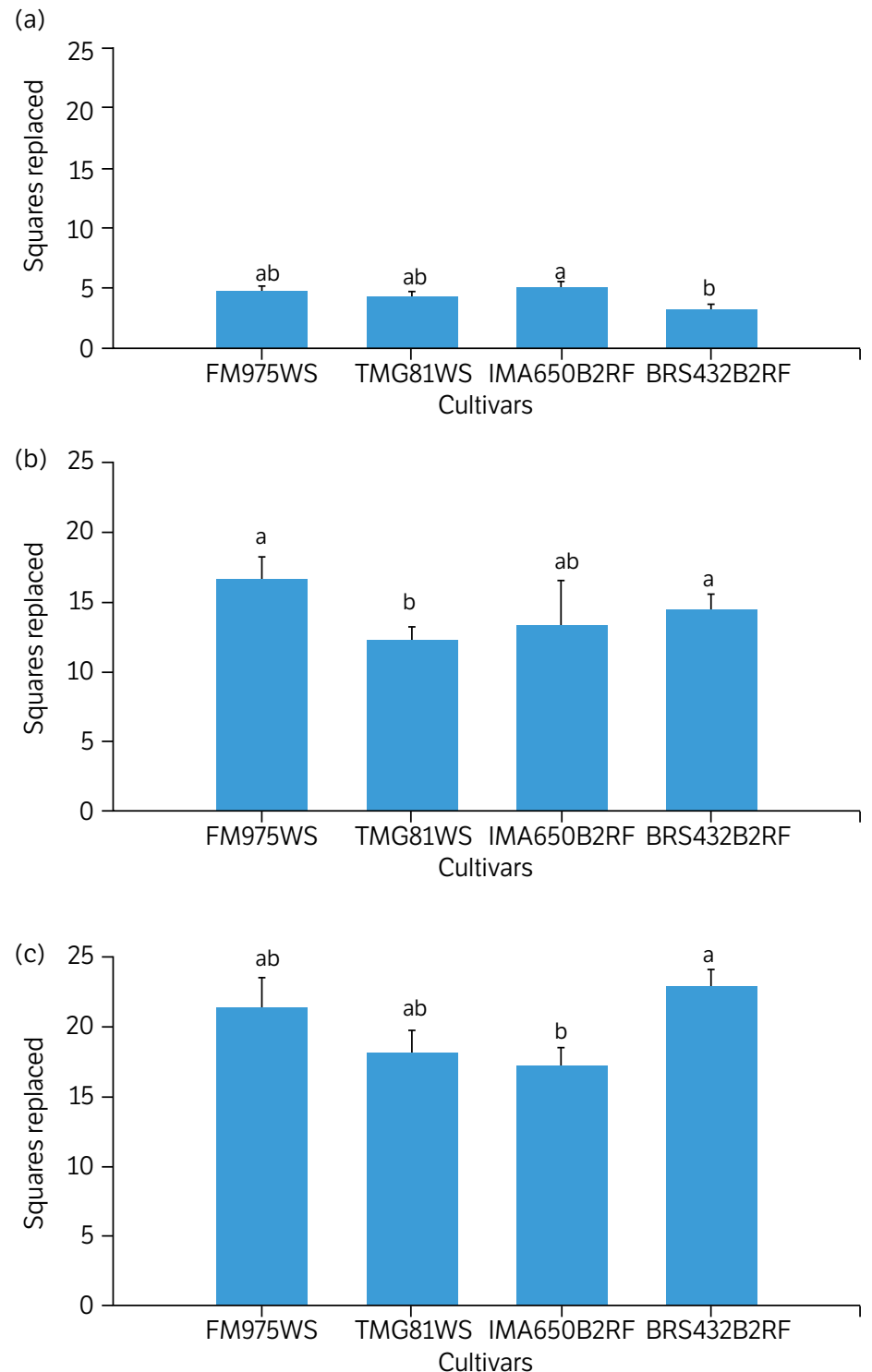

Figure 2. Total number of cotton squares, replaced per plant of the cotton cultivars after removal at 50 (a), 70 (b) and 90 (c) days of age.

Note. Means followed by the same lowercase letter, by bar and date, do not differ between cotton cultivars by the Student-Newman-Keuls test at $5 \%$ probability. Averages transformed into $\sqrt{ } x+0.5$ for the purposes of statistical analysis. Original means are shown.

The total numbers of cotton squares, produced in an active or passive way, after their removal at 50, 70 and 90 days, showed significant interaction between cultivars and forms of production $\left(\mathrm{F}_{3,213}=3.26 ; \mathrm{p}=0.02\right)$ at 50 days, differed between cultivars $\left(\mathrm{F}_{3,213}=5.09 ; \mathrm{p}=0.02\right)$ and forms of production at 70 days $\left(\mathrm{F}_{1,213}=295.84 ; \mathrm{p}<0.01\right)$ and in the form production $\left(\mathrm{F}_{1,213}=799.61 ; \mathrm{p}<0.01\right)$ at 90 days (Fig. $\left.3 \mathrm{a}-\mathrm{c}\right)$. The numbers of cotton squares, produced in an active way, were always higher than those in a passive way in all cultivars and removal periods, except in the TMG81WS at 50 days, with similarity between active and passive production of cotton squares. The total numbers of cotton squares, passively produced, after their removal at 50 days, was higher in the FM975WS, IMA6501B2RF and BRS432B2RF and lower in the TMG81WS. The total number of cotton squares, passively produced, after their removal at 70 days, was higher in the FM975WS and lower in the TMG81WS. At 90 days, the values were similar between all cultivars. 

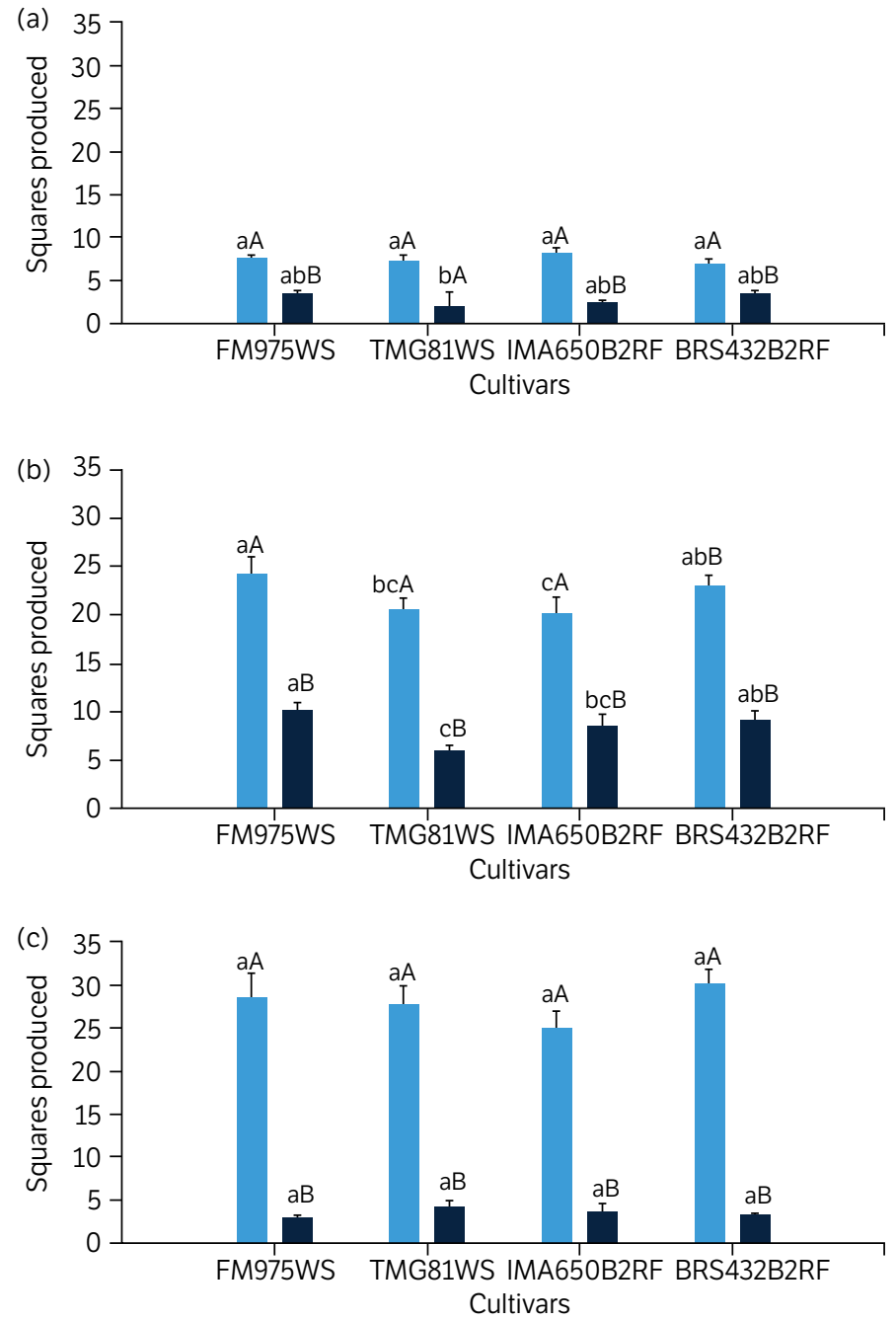

Figure 3. Total number of cotton squares produced actively (blue bar) and passively (dark blue bar), per plant, of the cotton cultivars after removal at 50 (a), 70 (b) and 90 (c) days of age.

Note. Means followed by the same lowercase letter, by cultivar and date, or uppercase, by type of production and date, do not differ by the Student-NewmanKeuls test at $5 \%$ probability. Means transformed into $\sqrt{x}+0.5$ for statistical analysis. Original means are shown.

The proportional production of cotton squares, in an active way, was higher in the TMG81WS and IMA6501B2RF after their removal at 50 days of age $\left(\mathrm{F}_{3,108}=4.24 ; \mathrm{p}<0.01\right)$, for the TMG81WS at 70 days $\left(\mathrm{F}_{3,108}=3.21 ; \mathrm{p}=0.02\right)$ and for the FM975WS and BRS432B2RF at 90 days $\left(\mathrm{F}_{3,108}=5.83 ; \mathrm{p}<0.01\right)($ Table 1$)$.

Table 1. Proportion between cotton squares produced actively or passively in the four cotton cultivars after their removal at 50,70 and 90 days of age from cotton plants.

\begin{tabular}{cccc}
\hline \multirow{2}{*}{ Cultivars } & \multicolumn{3}{c}{ Cotton squares removal periods } \\
\cline { 2 - 3 } & 50 days & $\mathbf{7 0}$ days & 90 days \\
\hline FM975WS & $1.5: 1.0 \mathrm{~b}$ & $1.6: 1.0 \mathrm{~b}$ & $3.0: 1.0 \mathrm{a}$ \\
\hline TMG81WS & $1.8: 1.0 \mathrm{a}$ & $1.8: 1.0 \mathrm{a}$ & $2.5: 1.0 \mathrm{~b}$ \\
\hline IMA6501B2RF & $1.9: 1.0 \mathrm{a}$ & $1.6: 1.0 \mathrm{~b}$ & $2.6: 1.0 \mathrm{~b}$ \\
\hline BRS432B2RF & $1.5: 1.0 \mathrm{~b}$ & $1.6: 1.0 \mathrm{~b}$ & $3.0: 1.0 \mathrm{a}$ \\
\hline
\end{tabular}

Note. Means followed by the same lowercase letter ${ }^{1}$, per column do not differ by the Student-Newman-Keuls test at $5 \%$ probability. Means transformed into $\sqrt{ } \mathrm{x}+0.5$ for statistical analysis. 
Compensations, after removing cotton squares, at $50\left(\mathrm{~F}_{3,213}=4.46 ; \mathrm{p}<0.01\right), 70\left(\mathrm{~F}_{3,213}=2.77 ; \mathrm{p}=0.05\right)$ and $90\left(\mathrm{~F}_{3,213}=3.62 ; \mathrm{p}=0.02\right)$ days of age of the plants, differed between cotton cultivars (Fig. $\left.4 \mathrm{a}-\mathrm{c}\right)$. The compensations of TMG81WS and IMA6501 were higher than those of BRS 432 B2RF and FM975WS with removal at 50 days of age, those of the TMG81WS and IMA6501B2RF were greater and lower, respectively, at 70 days and the values were similar between cultivars for removal at 90 days. The production of cotton squares, by compensation, increased in the removal periods of 50 and 90 days for all cultivars.
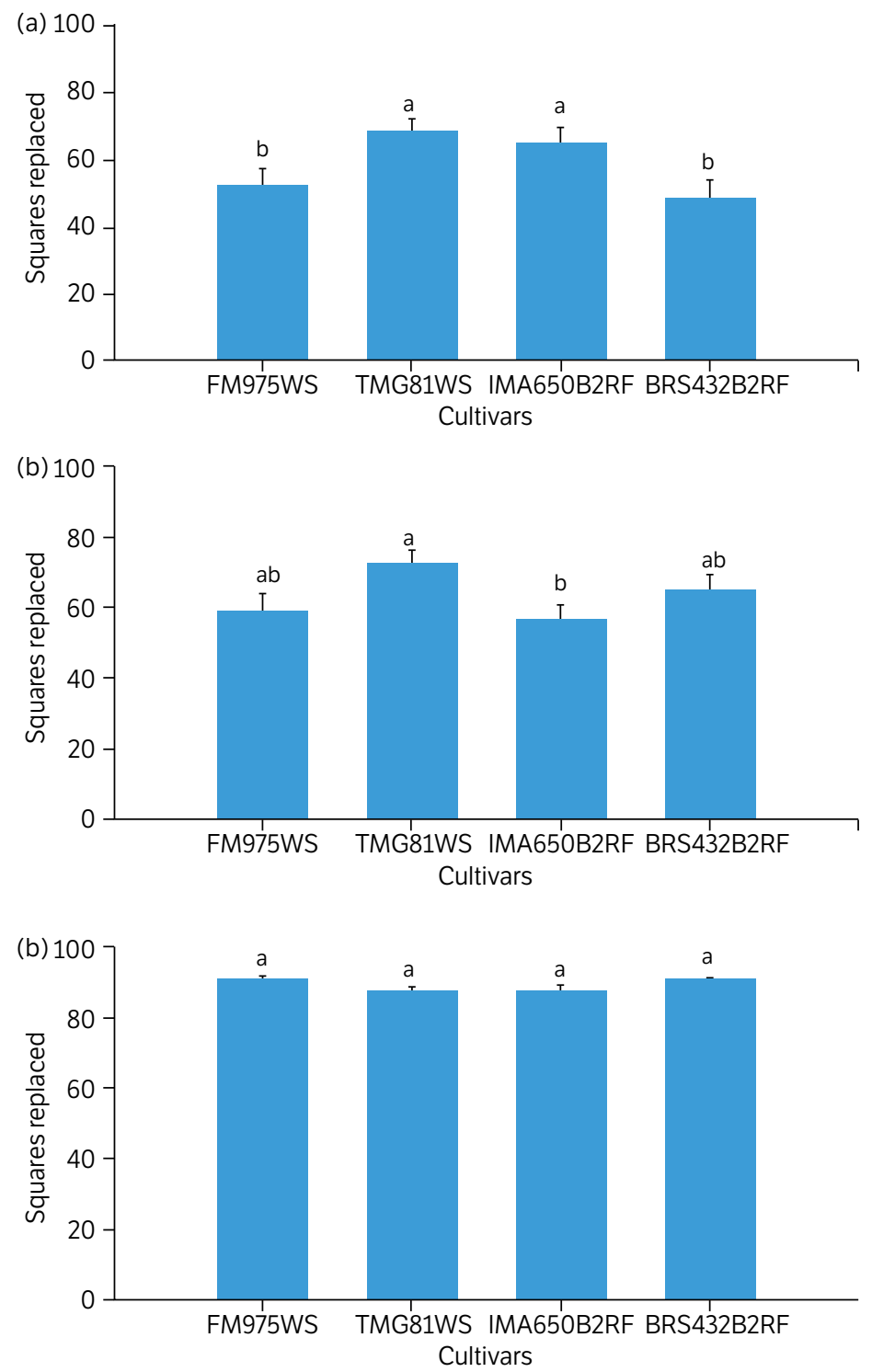

Figure 4. Compensation of cotton squares (\%) by cotton cultivars after removal at 50 (a), 70 (b) and 90 (c) days of age.

Note. Means followed by the same lowercase letter, by bar and date, do not differ between cotton cultivars by the Student-Newman-Keuls test at $5 \%$ probability.

\section{Boll weevil damage in cotton cultivars}

The percentage of cotton squares with punctures of feeding and/or oviposition by the boll weevil was similar between cotton cultivars $\left(\mathrm{F}_{1,9}=0.01 ; \mathrm{p}>0.05\right)$ (Table 2$)$, but differed between treatments $\left(\mathrm{F}_{1,9}=5.06 ; \mathrm{p}=0.05\right)$. The percentages of cotton squares damaged by the boll weevil were higher in the control and lower in the treatment sprayed with carbamate. 
Table 2. Cotton plants with cotton squares damaged by the cotton boll weevil with punctures of feeding and/or oviposition (\%), number of bolls and yield (g) per plant, cotton cultivar and treatment.

\begin{tabular}{|c|c|c|c|}
\hline \multirow{2}{*}{ Variables } & \multirow{2}{*}{ Treatments } & \multicolumn{2}{|c|}{ Cultivars } \\
\hline & & TMG81WS & BRS432B2FR \\
\hline \multirow{2}{*}{ Cotton squares damage (\%) } & Control & $13.44 \pm 4.06 \mathrm{aA}$ & $12.50 \pm 3.21 \mathrm{Aa}$ \\
\hline & Carbamate & $9.69 \pm 2.58 \mathrm{bA}$ & $10.31 \pm 1.76 \mathrm{bA}$ \\
\hline \multirow{2}{*}{ Number of bolls $\cdot$ plant $^{-1}$} & Control & $1.44 \pm 0.13 a \mathrm{~A}$ & $1.06 \pm 0.37 \mathrm{bB}$ \\
\hline & Carbamate & $1.50 \pm 0.07 a \mathrm{~A}$ & $1.49 \pm 0.10 a A$ \\
\hline \multirow{2}{*}{ Cotton production $\left(\mathrm{kg} \cdot \mathrm{ha}^{-1}\right)$} & Control & $1,335.50 \pm 2.21 \mathrm{aA}$ & $1,117.50 \pm 6.25 b B$ \\
\hline & Carbamate & $1,923.50 \pm 8.64 a \mathrm{~A}$ & $1,769.50 \pm 5.85 \mathrm{aA}$ \\
\hline
\end{tabular}

Note. Means followed by the same lowercase letter ${ }^{1}$, per column, or uppercase ${ }^{2}$, per line, and evaluated parameter, do not differ by the Student-Newman-Keuls test at $5 \%$ probability.

The mean number of bolls per cotton plant showed a significant interaction between treatments and cultivars $\left(\mathrm{F}_{1,57}=4.28 ; \mathrm{p}=0.04\right)$ (Table 2). The numbers of bolls were higher in the treatment sprayed with carbamate in the BRS432B2FR and TMG81W, but only for the TMG81WS in the control.

The cotton yield per plant varied between treatments $\left(\mathrm{F}_{1,57}=50.77 ; \mathrm{p}<0.01\right)$ and cultivars $\left(\mathrm{F}_{1,57}=4.77 ; \mathrm{p}=0.03\right)$ without significant interaction between these factors (Table 2). The cotton yield per plant was higher in the treatment with carbamate in all cotton cultivars, but in the control the yield was reduced by 30 and 37\% in the TMG81WS and BRS432B2RF, respectively, because of the abscissions of the cotton squares caused by the boll weevil damage. The TMG81WS yield was greater than that of BRS432B2RF in this treatment.

\section{DISCUSSION}

\section{Cotton evaluation based on compensatory increase in cotton squares}

The mean number of cotton squares removed, similar in the 50, 70 and 90 days between the cotton cultivars, differs from results for those of DPL NuCotn 33B, Paymaster 1244B and Paymaster 1220B (Stewart et al. 2001), with cotton squares removed at 50 and 70 days, which may be related to their productive potential (Khan et al. 2017).

The greatest replacement of cotton squares by the cotton plants of the IMA6501B2RF, FM975WS and BRS432B2RF and the lowest for the BRS432B2RF, TMG81WS and IMA6501B2RF, after removal at 50, 70 and 90 days, coincides with the period of higher production of these reproductive structures, with exponential increase from 38 to 90 days and decrease until 120 days of age of the plants (Su et al. 2015) and confirms variations between cotton cultivars (Koch et al. 2016). The response of the cultivar Siokra, to manual removal of cotton squares, to simulate damage by insect pests, was greater than that of the Deltapine 90 (Brook et al. 1992), but that of Bt (DPL NuCotn 33B, Paymaster 1244B and Paymaster 1220B) and non-Bt (Paymaster 1220) cotton were similar after removals at 50, 60 and 70 days (Stewart et al. 2001).

Significant interactions between the total numbers of cotton squares, produced actively and passively after their removal, between cultivars and forms of production at 50 days, cultivars and forms of production at 70 days and forms of production at 90 days may be due to differences in the replacement of cotton square losses by cotton cultivars, as reported for the Siokra (Brook et al. 1992) and Phytogen 375WRF (Kerns et al. 2016) ones. The early-maturing cotton cultivar DES119 was more susceptible to prolonged losses of cotton squares than the late-maturing Deltapina 90 (Mann et al. 1997). The cultivars tested were representative of those commonly grown in the Brazilian Cerrado with medium to late cycle, except the TMG81WS, due to its aggressive and vigorous root system, with greater adaptation to medium fertility soils and tolerance to gall nematodes (Silva Filho et al. 2016). This suggests that genotypic characteristics of this cultivar may influence its response to cotton square losses.

The higher proportional production of cotton squares actively in the TMG81WS, after their removal, at 50 days and 70 days of age, may be related to the vigorous root system of this cultivar (McNickle and Evans 2018). Cotton cultivars with 
a more vigorous root system can produce a greater number of cotton squares, actively, in critical periods of physiological abscission from the plant and with greater compensatory capacity (Oosterhuis and Cothren 2012). This compensation type is classified as time-dependent because the loss of cotton reproductive structures slows down its metabolic stress, prolongs the cotton square production and facilitates the transformation of its additional reproductive structures into bolls (Hearn and Room 1979).

Differences between the compensatory response to cotton squares removal at 50,70 and 90 days between the cultivars of cotton plants is similar to that obtained for those replaced and, apparently, is related to their greater capacity to produce, proportionally, greater number of cotton squares actively by having a vigorous root system increasing the plant regrowth potential (Oosterhuis and Cothren 2012). This explains the greater compensatory capacity of the TMG81WS, whose root system is more vigorous than that of the other cultivars tested (Silva Filho et al. 2016), but it also depends on the period in which the abscission occurred (Khan et al. 2017). The compensatory response for the cotton square losses, artificially removed from the plant, by all cotton cultivars may be due by this plant structure being smaller than the bolls and, therefore, with lower investment in resources and time to be produced by cotton plants (Garcia and Eubanks 2019; Stewart et al. 2001). This is important for the management of the boll weevil, as its females prefer to feed on cotton squares than on bolls (Ramalho and Jesus 1988), due to the need to consume pollen to develop their ovaries and lay fertile eggs (Showler and Abrigo 2007; Showler 2008).

\section{Boll weevil damage in cotton cultivars}

The similar percentages of cotton squares damaged by the boll weevil, per cultivar, and difference among treatments are probably due to the efficiency of the insecticide carbamate to reduce populations of this pest (Ramalho and Jesus 1989). This agrees with that reported for Bt and non-Bt cotton cultivars after the application of insecticides to control caterpillars of Heliothis virescens (Fabricius 1781) and Helicoverpa zea (Boddie 1850) (Lepidoptera: Noctuidae) (Stewart et al. 2001), masking potential differences in susceptibility of cotton cultivars to square losses due to the population reduction of these lepidopterans-pest. This may have contributed to modify the response of both plant cultivars to cotton square abscissions due to the damage caused by the boll weevil. In addition, it explains the lower percentage of cotton squares damaged by the boll weevil in the sprayed treatment with carbamate than in the control.

The interaction between the mean numbers of bolls per cotton plant indicates that this parameter varies between treatments and cultivars, with the largest numbers in those treated with carbamate due to the efficient control of the boll weevil. In addition, the greater number of bolls in the TMG81WS indicates resistance by tolerance, compensating losses by this insect pest (Koch et al. 2016). This may be due to the greater capacity of the TMG81WS to actively compensate the removal of cotton squares after the 50 and 70 days of age of the plants (first experiment).

The similar yield of cotton in the treatment with carbamate is due to the efficient control of the boll weevil, as reported in experiments to evaluate the efficiency of insecticides against this pest (Ramalho and Jesus 1989). The reduction in yield by 30 and 37\% in the TMG81WS and BRS432B2RF, respectively, is lower than the 50-60\% reduction caused by the boll weevil in the Coker $100 \mathrm{~W}$ (Mistric Junior and Covington 1968). This is probably due to the greater productive potential of the cotton cultivars used in this work compared to the old Coker $100 \mathrm{~W}$. In addition, the higher production of the TMG81WS (control) is due to its greater tolerance resistance compared to BRS432B2RF as reported for the Siokta (Brook et al. 1992) and Phytogen 375WRF (Kerns et al. 2016).

\section{CONCLUSION}

The compensatory increase of cotton squares, mainly after artificial removal at 50 and 70 days after emergence, was greater in the TMG81WS cotton cultivar. The compensatory increase of cotton squares artificially removed from cotton cultivars was greater during the period of exponential production of these reproductive structures and can be used to select cotton cultivars tolerant to damage by the boll weevil. 


\section{AUTHORS' CONTRIBUTION}

Conceptualization: Alves, B. L. N. and Silva, C. A. D.; Methodology: Alves, B. L. N. and Silva, C. A. D.; Investigation: Alves, B. L. N.; Writing - Original Draft: Alves, B. L. N., Silva, C. A. D., Serrão, J. E., Zanuncio, J. C.; Writing - Review and Editing: Alves, B. L. N., Silva, C. A. D., Serrão, J. E., Zanuncio, J. C.; Funding Acquisition: Alves, B. L. N.; Supervision: Silva, C. A. D.

\section{DATA AVAILABILITY STATEMENT}

The data will be available upon request.

\section{FUNDING}

Coordenação de Aperfeiçoamento de Pessoal de Nível Superior

[https://doi.org/10.13039/501100002322]

Finance Code 001

\section{ACKNOWLEDGMENTS}

Not applicable.

\section{REFERENCES}

Abbott, W. S. (1925). A method of computing the effectiveness of an insecticide. Journal of Economic Entomology, 18, 265-267. https:// doi.org/10.1093/jee/18.2.265a

Anderson, J. A., Ellsworth, P. C., Faria, J. C., Head, G. P., Owen, M. D. K., Pilcher, C. D., Shelton, A. M. and Meissle, M. (2019). Genetically engineered crops: importance of di-versified integrated pest management for agricultural sustainability. Frontiers in Bioengineering and Biotechnology, 7, 24. https://doi.org/10.3389/fbioe.2019.00024

Brook, K. D., Hearn, A. B. and Kelly, C. F. (1992). Response of cotton, Gossypium hirsutum L., to damage by insect pests in Australia: Manual simulation of damage. Journal of Economic Entomology, 85, 1368-1377. https://doi.org/10.1093/jee/85.4.1368

Carvalho, L. P., Lukefhar, M. J., Farias, F. J. C., Vieira, R. M., Moreira, J. A. N. and Costa, J. N. (1996). Seleção de algodoeiro com resistência ao bicudo. Pesquisa Agropecuária Brasileira, 31, 195-199.

Garcia, L. C. and Eubanks, M. D. (2019). Overcompensation for insect herbivory: a review and meta-analysis of the evidence. Ecology, 100, e02585. https://doi.org/10.1002/ecy.2585

Hearn A. B. and Room, P. M. (1979). Analysis of crop development for cotton pest management. Protection Ecology, 1, $265-277$.

Kerns, D. L., Fromme, D. D., Baugh, B. A. and Doederlein, T. (2016). Ability of cotton on the Texas High Plains to compensate for prebloom square loss and impact on yield and fiber quality. Journal of Cotton Science, 20, 103-115.

Khan, A., Tan, D. K. Y., Afridi, M. Z., Luo, H., Tung, S. A., Ajab, M. and Fahad, S. (2017). Nitrogen fertility and abiotic stresses management in cotton crop: a review. Environmental Science and Pollution Research, 24, 14551-14566. https://doi.org/10.1007/s11356-017-8920-x 
Knutson, A. E., Mekala, K. D., Smith, C. W. and Campos, C. (2013). Tolerance to feeding damage by cotton fleahopper (Hemiptera: Miridae) among genotypes representing adapted germplasm pools of United States upland cotton. Journal of Economic Entomology, 106, 1045-1052. https://doi.org/10.1603/EC12421

Koch, K. G., Chapman, K., Louis, J., Heng-Moss, T. and Sarath, G. (2016). Plant tolerance: a unique approach to control hemipteran pests. Frontiers in Plant Science, 7, 1363. https://doi.org/10.3389/fpls.2016.01363

Mann, J. E., Turnipseed, S. G., Sullivan, M. J., Adler, P. H. and May, O. L. (1997). Effects of early-season loss of flower buds on yield, quality, and maturity of cotton in South Carolina. Journal of Economic Entomology, 90, 1324-1331. https://doi.org/10.1093/jee/90.5.1324

McNickle, G. G. and Evans, W. D. (2018). Toleration games: compensatory growth by plants in response to enemy attack is an evolutionarily stable strategy. AoB PLANTS, 10, ply035. https://doi.org/10.1093/aobpla/ply035

Mistric Junior, W. J. and Covington B. M. (1968). Effects of square removal on cotton production with reference to boll weevil damage. Journal of Economic Entomology, 61, 1060-1067. https://doi.org/10.1093/jee/61.4.1060

Oliveira, C. M., Auad, A. M., Mendes, S. M. and Frizzas, M. R. (2013). Economic impact of exotic insect pests in Brazilian agriculture. Journal of Applied Entomology, 137, 1-15. https://doi.org/10.1111/jen.12018

Oosterhuis, D. M. and Cothren, J. T. (2012). Flowering and fruiting in cotton. Cordova: The Cotton Foundation.

Peterson, R. K. D., Varella, A. C. and Higley, L. G. (2017). Tolerance: the forgotten child of plant resistance. PeerJ, 5, e3934. https://doi. org/10.7717/peerj.3934

Ramalho, F. S. and Jesus, F. M. M. (1988). Distribution of boll weevil (Anthonomus grandis Boheman) eggs within cotton plants. Tropical Agriculture, 65, 245-248.

Ramalho, F. S. and Jesus, F. M. M. (1989). Avaliação de inseticidas para o controle do bicudo-do-algodoeiro. Pesquisa Agropecuária Brasileira, 24, 273-276.

Ribeiro Junior, J. I. (2001). Análises estatísticas no SAEG. Viçosa: UFV.

Rocha-Munive, M. G., Soberon, M., Castaneda, S., Niaves, E., Scheinvar, E., Eguiarte, L. E., Mota-Sánchez, D., Rosales-Robles, E., NavaCamberos, U., Martínez-Carrillo, J. L., Blanco, C. A., Bravo, A. and Souza, V. (2018). Evaluation of the impact of genetically modified cotton after 20 years of cultivation in Mexico. Frontiers in Bioengineering and Biotechnology, 6, 82. https://doi.org/10.3389/fbioe.2018.00082

Sadras, V. O. (1995). Compensatory growth in cotton after loss of reproductive organs. Field Crops Research, 40, 1-18. https://doi. org/10.1016/0378-4290(94)00088-T

Salvador, R., Príncipi, D., Berretta, M., Fernandez, P., Paniego, N., Sciocco-Cap, A. and Hopp, E. (2014). Transcriptomic survey of the midgut of Anthonomus grandis (Coleoptera: Curculionidae). Journal of Insect Science, 14, 219. https://doi.org/10.1093/jisesa/ieu081

Showler, A. T. (2008). Relationships of abscised cotton fruit to boll weevil (Coleoptera: Curculionidae) feeding, oviposition, and development. Journal of Economic Entomology, 101, 68-73. https://doi.org/10.1093/jee/101.1.68

Showler, A. T. and Abrigo, V. (2007). Common subtropical and tropical nonpollen food sources of the boll weevil (Coleoptera: Curculionidae). Environmental Entomology, 36, 99-104. https://doi.org/10.1093/ee/36.1.99

Silva, C. A. D. and Ramalho, F. S. (2013). Kaolin spraying protects cotton plants against damages by boll weevil Anthonomus grandis Boheman (Coleoptera: Curculionidae). Journal of Pest Science, 86, 563-569. https://doi.org/10.1007/s10340-013-0483-0

Silva, A. L. A. L. and Silva, C. A. D. (2015). Concentração eficiente e econômica de caulim para a proteção de algodoeiro contra o bicudo. Pesquisa Agropecuária Brasileira, 50, 763-768. https://doi.org/10.1590/S0100-204X2015000900004

Silva, C. A. D., Ramalho, F. S., Miranda, J. E., Almeida, R. P., Rodrigues, S. M. M. and Albuquerque, F. A. (2013) Sugestões técnicas para o manejo integrado de pragas do algodoeiro no Brasil [Circular Técnica 135]. Campina Grande: Embrapa. 
Silva Filho, J. L., Pedrosa, M. B., Suassuna, N. D., Morello, C. L., Farias, F. J. C. and Perina, F. J. (2016). Avaliação de cultivares de algodoeiro no Cerrado da Bahia, Safra 2014/2015 [Documentos 260]. Campina Grande: Embrapa.

Stewart, S. D., Layton, M. B., Williams, M. R., Ingram, D. and Maily, W. (2001). Response of cotton to prebloom square loss. Journal of Economic Entomology, 94, 388-396. https://doi.org/10.1603/0022-0493-94.2.388

Su, L., Wang Q., Wang, C. and Shan, Y. (2015). Simulation models of leaf area index and yield for cotton grown with different soil conditioners. PLoS ONE, 10, e0141835. https://doi.org/10.1371/journal.pone.0141835 